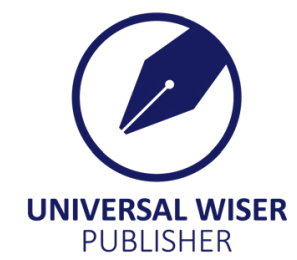

\title{
Multi-objective Optimization of Welding Parameters of Pulsed Current Micro Plasma Arc Welded AISI 904L Super Austenitic Steel
}

\author{
M. Sailaja ${ }^{1^{*}}$, K. Ramji ${ }^{2}$ \\ ${ }^{1}$ Department of Mechanical Engineering, Anil Neerukonda institute of Technology and Sciences, Visakhapatnam, India \\ ${ }^{2}$ Department of Mechanical Engineering, Andhra University, Visakhapatnam, India \\ ${ }^{1}$ Email: saisailaja2k@gmail.com \\ 르ail: ramjidme@gmail.com
}

\begin{abstract}
In the present work, AISI 904L super austentic steel sheets of $0.4 \mathrm{~mm}$ thick is butt welded using Micro Plasma Arc Welding. Welding input parameters like peak current, base current, pulse rate and pulse width are considered and output responses like fusion zone grain size, hardness and ultimate tensile strength of the welded joint are considered. 31 experiments are performed as per Central Composite Design (CCD) design matrix of Response Surface Method (RSM) by considering four factors and five levels of weld input parameters. Grey Relational Analysis (GRA) is carried out by minimizing fusion zone grain size and maximizing fusion zone hardness and ultimate tensile strength to find the optimal combination of weld input parameters. The order of importance of weld input parameters are also identified and improvement in Grey Relational Grade was found.

Keywords: Micro Plasma Arc Welding, AISI 904L, RSM, Grey Relational Analysis
\end{abstract}

\section{Introduction}

Stainless steels are well known metal alloy for corrosion resistance. All stainless steels are iron base alloy sconsist $10 \%$ or more chromium. Chromium is the major element which responsible for corrosion resistance, although other elements, particularly nickel and molybdenum, are added to improve corrosion resistance. There are different types of stainless steels that are currently available one of those is austenitic stain less steel.

Austenitic stainless steels are the common and familiar type of stainless steel they are most easily recognized as nonmagnetic and they are widely used in various industries as structural material, as they possess a combination of properties like high strength and ductility, good formability and versatile fabricability ${ }^{[1]}$.

Super austenitic stainless steels are highly alloyed iron-nickel-chromium stainless steel, containing molybdenum have been developed to respond to severe corrosion specifications. Superaustenitic stainless steels exhibit great resistance to chloride pitting and crevice corrosion because of high molybdenum content, and the higher nickel content ensures better resistance to stress-corrosion cracking ${ }^{[2-3]}$. Super-austenitic stainless steels are widely used in marine, petrochemical and nuclear industries due to their excellent strength and corrosion resistance, and are preferred in aggressive environments. It has been reported that these steels have improved properties such as weldability, formability compared to the conventional stainless steels ${ }^{[4-6]}$.

AISI 904L is a kind of super austenitic stainless steel, which has high strength, high hardness, good impact toughness and welding performance with low carbon, high nickel, chromium, and a small amount of copper alloy system ${ }^{[7,8]}$. The joining of super austenitic stainless steel can be done with several welding process but, for thin sheets previous researches proved that pulsed current micro plasma arc welding provides good mechanical properties without damaging metal sheets $^{[9-11]}$.

In the present work Pulsed Current Micro Plasma Arc Welding (MPAW) is used to join AISI 904L super austentic steel sheets of $0.4 \mathrm{~mm}$ thick. Welding input parameters like peak current, base current, pulse rate and pulse width are considered and output responses like fusion zone grain size, hardness and ultimate tensile strength of the welded joint are considered. The objective of the paper is to optimize welding parameters namely peak current, base current, pulse rate and pulse width in order to minimize fusion zone grain size and maximize fusion zone hardness and ultimate tensile strength using Grey Relational Analysis. 


\section{Experimentation}

AISI 904L super austenitic steel of $0.4 \mathrm{~mm}$ thick sheets of $100 \times 150 \times 0.4 \mathrm{~mm}$ are welded autogenously with square butt joint without edge preparation. The chemical composition and tensile properties of AISI 904L sheets of $0.4 \mathrm{~mm}$ thick sheet is given in Table $1 \& 2$. High purity argon gas (99.99\%) is used as a shielding gas and a trailing gas right after welding to prevent absorption of oxygen and nitrogen from the atmosphere. The welding has been carried out under the welding conditions presented in Table 3. There are many influential process parameters which effect the weld quality characteristics of Pulsed Current MPAW process like peak current, back current, pulse rate, pulse width, flow rate of shielding gas, flow rate of purging gas, flow rate of plasma gas, welding speed etc. From the earlier works ${ }^{[12-14]}$ carried out on Pulsed Current MPAW it was understood that the peak current, back current, pulse rate and pulse width are the dominating parameters which effect the weld quality characteristics. The values of process parameters used in this study are the optimal values obtained from our earlier papers ${ }^{[12-14]}$. Hence peak current, back current, pulse rate and pulse width are chosen and their values are presented in Table 4. Details about experimental setup are shown in Figure 1.

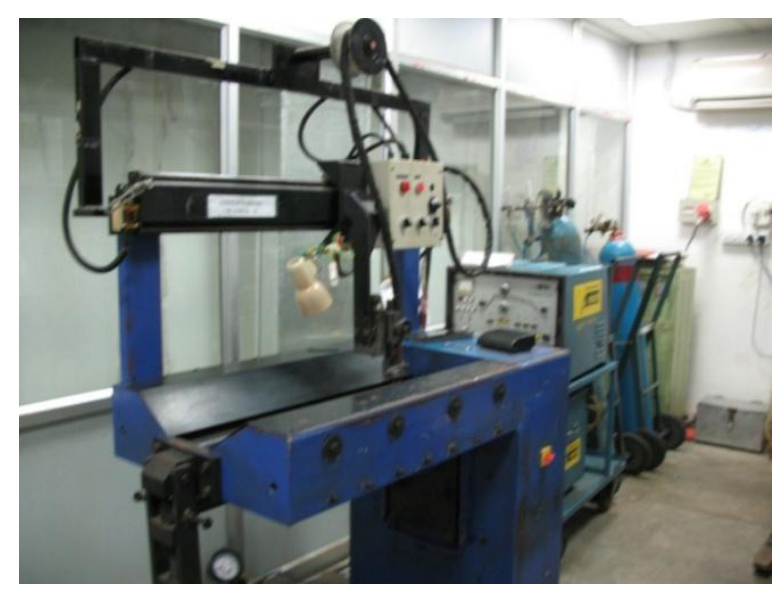

Figure 1. Micro Plasma Arc Welding Setup

Table 1. Chemical composition of AISI 904L (weight \%)

\begin{tabular}{cccccccc}
\hline $\mathrm{C}$ & $\mathrm{Mn}$ & $\mathrm{Cr}$ & $\mathrm{Ni}$ & $\mathrm{Mo}$ & $\mathrm{Cu}$ & $\mathrm{N}$ & $\mathrm{Fe}$ \\
\hline 0.0074 & 1.56 & 19.92 & 24.75 & 4.33 & 1.43 & 0.069 & 47.9336 \\
\hline
\end{tabular}

Table 2. Tensile properties of AISI 904L

\begin{tabular}{cccc}
\hline Elongation(\%) & YieldStrength $(\mathrm{MPa})$ & $\begin{array}{c}\text { UltimateTensile } \\
\text { Strength }(\mathrm{Mpa})\end{array}$ & $\begin{array}{c}\text { Hardness } \\
(\mathrm{VHN})\end{array}$ \\
\hline 36 & 220 & 573 & 242 \\
\hline
\end{tabular}


Table 3. Welding conditions

\begin{tabular}{ll}
\hline Power source & Secheron Micro Plasma Arc Machine (Model: \\
& PLASMAFIX 50E) \\
Polarity & DCEN \\
Mode of operation & Pulse mode \\
Electrode & $2 \%$ thoriated tungsten electrode \\
Electrode Diameter & $1 \mathrm{~mm}$ \\
Plasma gas & Argon \& Hydrogen \\
Plasma gas flow rate & $6 \mathrm{Lpm}$ \\
Shielding gas & Argon \\
Shielding gas flow rate & $6 \mathrm{Lpm}$ \\
Purging gas & Argon \\
Purging gas flow rate & $4 \mathrm{Lpm}$ \\
Copper Nozzle diameter & $1 \mathrm{~mm}$ \\
Nozzle to plate distance & $1 \mathrm{~mm}$ \\
Welding speed & $230 \mathrm{~mm} / \mathrm{min}$ \\
Torch Position & Vertical \\
Operation type & Automatic \\
\hline
\end{tabular}

Table 4. Process parameters and their limits

\begin{tabular}{cccccc}
\hline & -2 & -1 & 0 & +1 & +2 \\
\hline Peak Current (Amperes) & 16 & 18 & 20 & 22 & 24 \\
Base Current (Amperes) & 8 & 9 & 10 & 11 & 12 \\
Pulse Rate & 30 & 40 & 50 & 60 & 70 \\
$\begin{array}{c}\text { (Pulses/sec) } \\
\text { Pulse Width (\%) }\end{array}$ & 40 & 50 & 60 & 70 & 80 \\
\hline
\end{tabular}

\subsection{Measurement of Grain Size}

Three metallurgical samples are cut from each joint leaving the edges of defective portion of the welded length. Defective length of weld is identified visually and also by conducting dye pentrant and X-ray tests and mounted using Bakelite. Sample preparation and mounting is done as per ASTM E 3-1 standard. The transverse face of the samples are surface ground using 120 grit size belt with the help of belt grinder and polished sequentially using grade 1/0 (245 mesh size), grade 2/0 (425 mesh size) and grade 3/0 (515 mesh size) sand paper. The specimens are further polished using aluminum oxide, diamond paste and velvet cloth on a disc polishing machine. The polished specimens are macro-etched using aquaregia solution (three parts $\mathrm{HCl}$ and one part $\mathrm{HNO}_{3}$ ) to reveal the microstructure.

By varying the etching time microstructure and grain size of the weld zone are revealed. The micrograph of heat affected zone is shown in Figure 2 and weld fusion zone is shown in Figure. 3 at $100 \mathrm{X}$ magnifications. The grain sizes are measured randomly in the weld heat affected zone (HAZ), as failure takes place in this region for most of the weld samples and the measured values are presented in Table 5. 


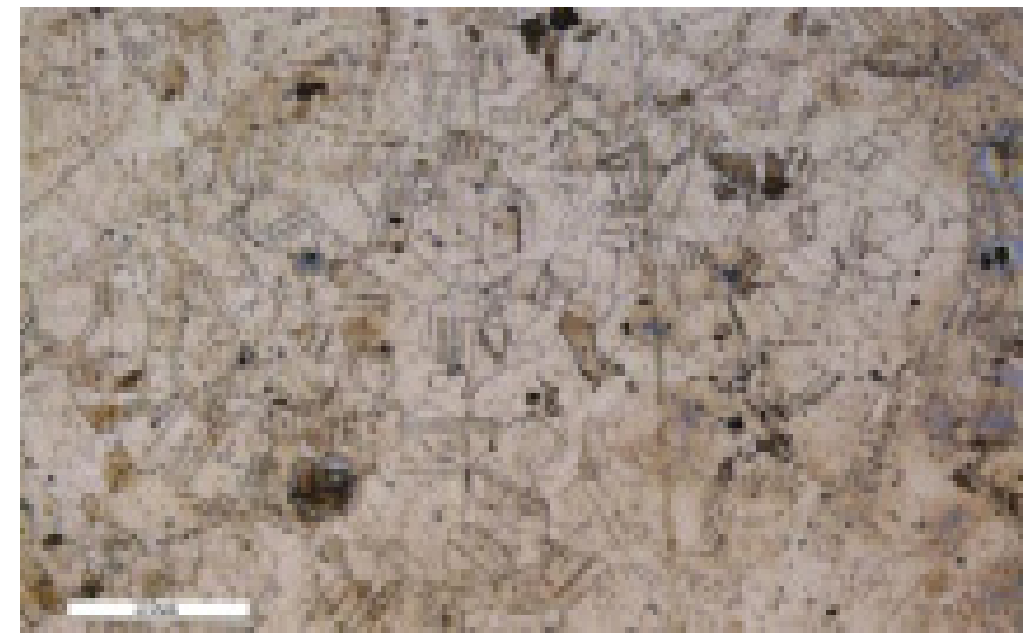

Figure 2. Microstructure of heat effected zone

From figure 3, it is understood that the weldments consist of a columnar dentritic structure. A pronounced acicular $\delta$-ferrite formation (dark etching) is observed around the cellular dentritic austenitic grain.

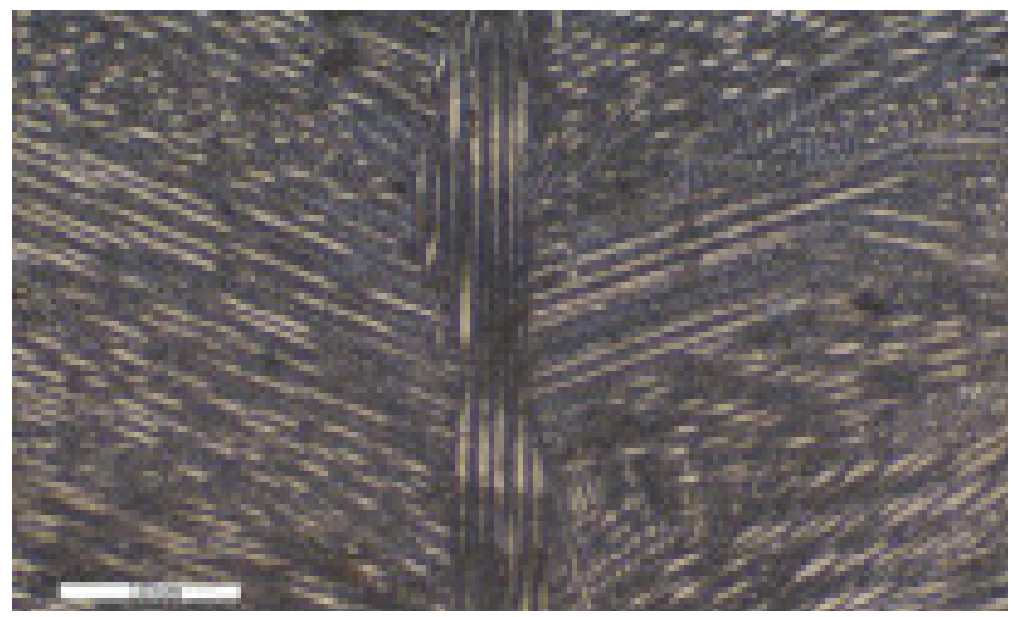

Figure 3. Microstructure of weld fusion zone

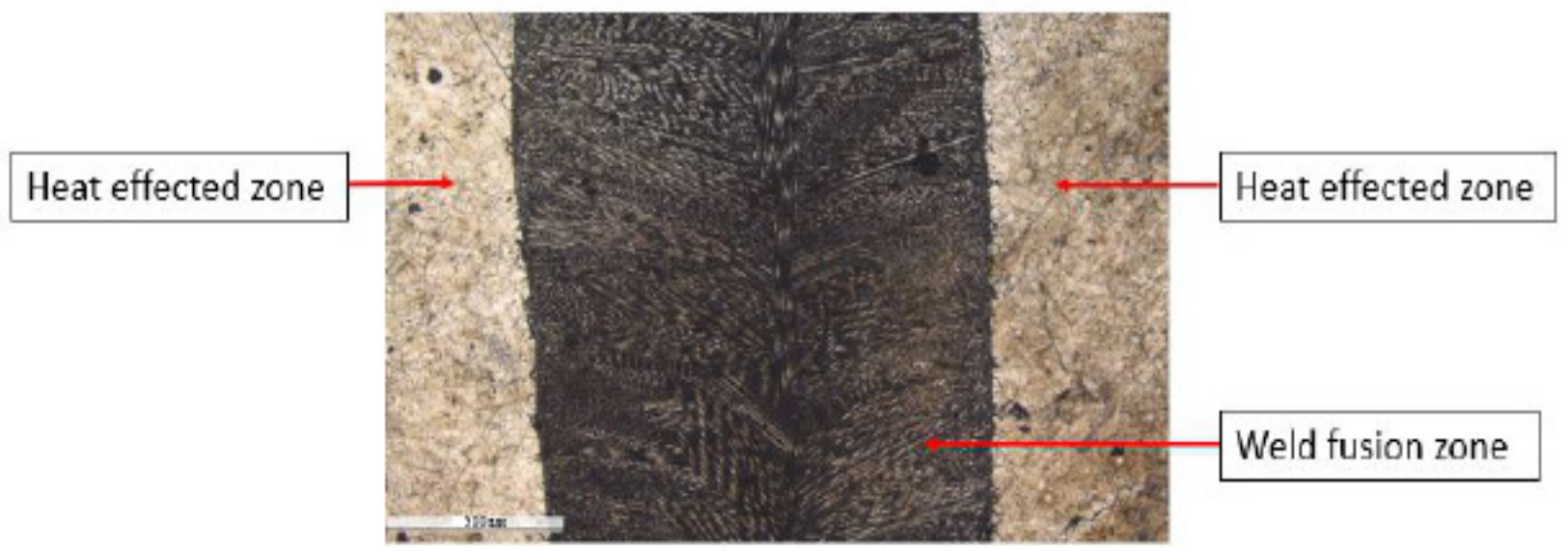

Figure 4. Microstructure of weld fusion zone and HAZ 


\subsection{Measurement of Fusion Zone Hardness}

The hardness of the weld fusion zone of the welded samples are measured using Vicker's micro hardness testing machine (Make: METSUZAWA CO LTD, JAPAN, Model: MMT-X7) by applying a load of 0.5 Kg as per ASTM E384. Average values of three readings of each sample are presented in Table 5. Hardness was measured across the weld fusion zone ( FZ) with a dwell time of 30 seconds and at an interval of $0.3 \mathrm{~mm}$.

\subsection{Measurement of Ultimate Tensile Strength (UTS)}

Tensile specimens are prepared as per ASTM E8M-04 guidelines using wire cut Electro Discharge Machining (Figure 5 ) in the transverse direction of the weld from each welded sample. Tensile tests are carried out on $100 \mathrm{KN}$ computer controlled Universal Testing Machine (Model No: 9036TD, Sr.No.STS-522, Star Testing Systems). The specimen is loaded at a rate of $1.5 \mathrm{KN} / \mathrm{min}$ as per ASTM specifications, so that the tensile specimens undergo deformation. From the stress strain curve (Figure 6), the ultimate tensile strength of the weld joints is evaluated and the average of the results of each sample is presented in Table 5.

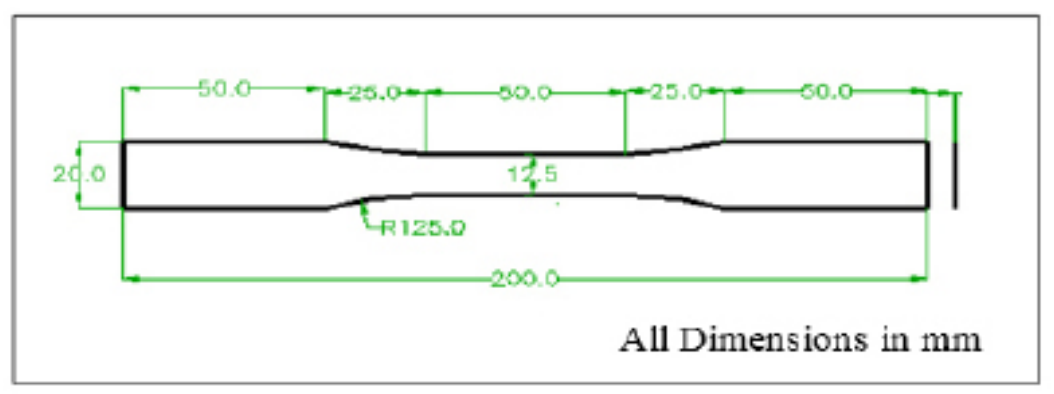

Figure 5. Tensile specimen as per ASTM E8M-04

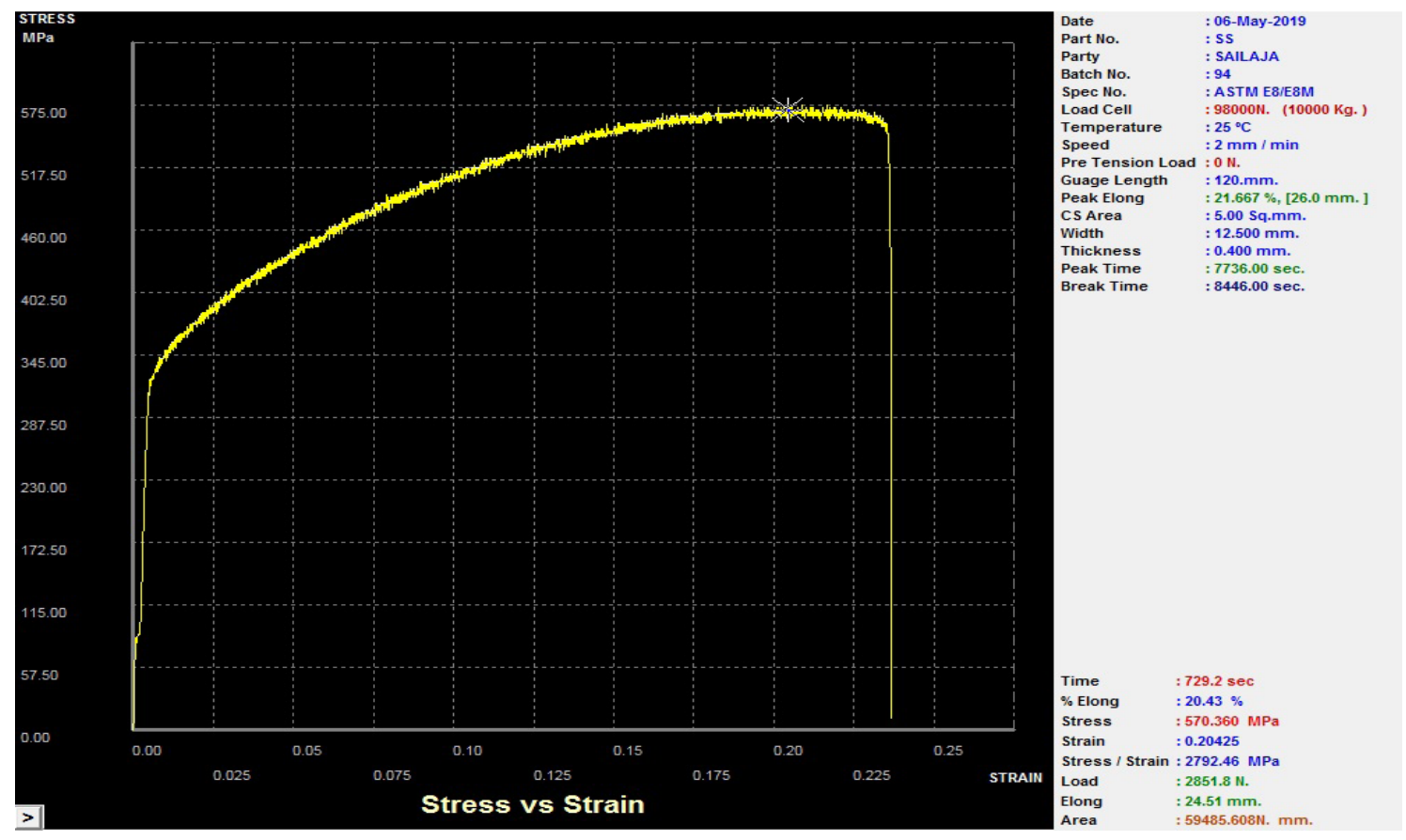

Figure 6. Stress strain curve 


\begin{tabular}{|c|c|c|c|c|c|c|c|}
\hline \multirow[b]{2}{*}{ SI. No } & \multicolumn{4}{|c|}{ INPUT PARAMETERS } & \multicolumn{3}{|c|}{$\begin{array}{l}\text { OUTPUT PARAMETERS } \\
\text { EXPERIMENTAL }\end{array}$} \\
\hline & $\begin{array}{c}\text { Peak Current } \\
\text { (Amperes) }\end{array}$ & $\begin{array}{c}\text { Base Current } \\
\text { (Amperes) }\end{array}$ & $\begin{array}{l}\text { Pulse Rate } \\
\text { (Pulses/sec) }\end{array}$ & $\begin{array}{c}\text { Pulse } \\
\text { Width } \\
(\%)\end{array}$ & $\begin{array}{l}\text { Grain size } \\
\text { (Microns) }\end{array}$ & $\begin{array}{c}\text { Hardness } \\
\text { (VHN) }\end{array}$ & $\begin{array}{c}\text { UTS } \\
\text { (MPa) }\end{array}$ \\
\hline 1 & 18 & 9 & 40 & 50 & 68.4 & 257 & 530 \\
\hline 2 & 22 & 9 & 40 & 50 & 67.6 & 266 & 554 \\
\hline 3 & 18 & 11 & 40 & 50 & 70.2 & 267 & 538 \\
\hline 4 & 22 & 11 & 40 & 50 & 68.3 & 277 & 546 \\
\hline 5 & 18 & 9 & 60 & 50 & 70.8 & 255 & 530 \\
\hline 6 & 22 & 9 & 60 & 50 & 73.9 & 263 & 540 \\
\hline 7 & 18 & 11 & 60 & 50 & 69.4 & 269 & 524 \\
\hline 8 & 22 & 11 & 60 & 50 & 70.8 & 279 & 542 \\
\hline 9 & 18 & 9 & 40 & 70 & 76.2 & 255 & 518 \\
\hline 10 & 22 & 9 & 40 & 70 & 68.4 & 259 & 528 \\
\hline 11 & 18 & 11 & 40 & 70 & 73.4 & 255 & 526 \\
\hline 12 & 22 & 11 & 40 & 70 & 66.4 & 276 & 546 \\
\hline 13 & 18 & 9 & 60 & 70 & 76.4 & 247 & 522 \\
\hline 14 & 22 & 9 & 60 & 70 & 68.8 & 249 & 540 \\
\hline 15 & 18 & 11 & 60 & 70 & 70.2 & 253 & 532 \\
\hline 16 & 22 & 11 & 60 & 70 & 63.6 & 273 & 546 \\
\hline 17 & 16 & 10 & 50 & 60 & 75.8 & 247 & 506 \\
\hline 18 & 24 & 10 & 50 & 60 & 66.8 & 262 & 547 \\
\hline 19 & 20 & 8 & 50 & 60 & 72.6 & 251 & 518 \\
\hline 20 & 20 & 12 & 50 & 60 & 66.8 & 277 & 542 \\
\hline 21 & 20 & 10 & 30 & 60 & 68.6 & 265 & 540 \\
\hline 22 & 20 & 10 & 70 & 60 & 70.8 & 261 & 534 \\
\hline 23 & 20 & 10 & 50 & 40 & 69.6 & 271 & 548 \\
\hline 24 & 20 & 10 & 50 & 80 & 71.12 & 255 & 527 \\
\hline 25 & 20 & 10 & 50 & 60 & 70.6 & 265 & 539 \\
\hline 26 & 20 & 10 & 50 & 60 & 69.8 & 267 & 537 \\
\hline 27 & 20 & 10 & 50 & 60 & 70.6 & 265 & 539 \\
\hline 28 & 20 & 10 & 50 & 60 & 68.8 & 267 & 537 \\
\hline 29 & 20 & 10 & 50 & 60 & 69.6 & 265 & 539 \\
\hline 30 & 20 & 10 & 50 & 60 & 68.8 & 267 & 537 \\
\hline 31 & 20 & 10 & 50 & 60 & 70.2 & 269 & 540 \\
\hline
\end{tabular}

\section{Optimization}

\subsection{Optimal Solution from RSM}

Figure 7 indicates the optimal solution of Response Surface method for minimum grain size and maximum hardness and UTS. From the figure, it is understood that at peak current 24 Amperes, base current 12 Amperes, pulse rate 70 pulses/ sec and pulse width $80 \%$, the optimal grain size of 49.7257 microns, hardness of 270.0476 VHN and UTS of 558.4762 $\mathrm{MPa}$ is obtained. 


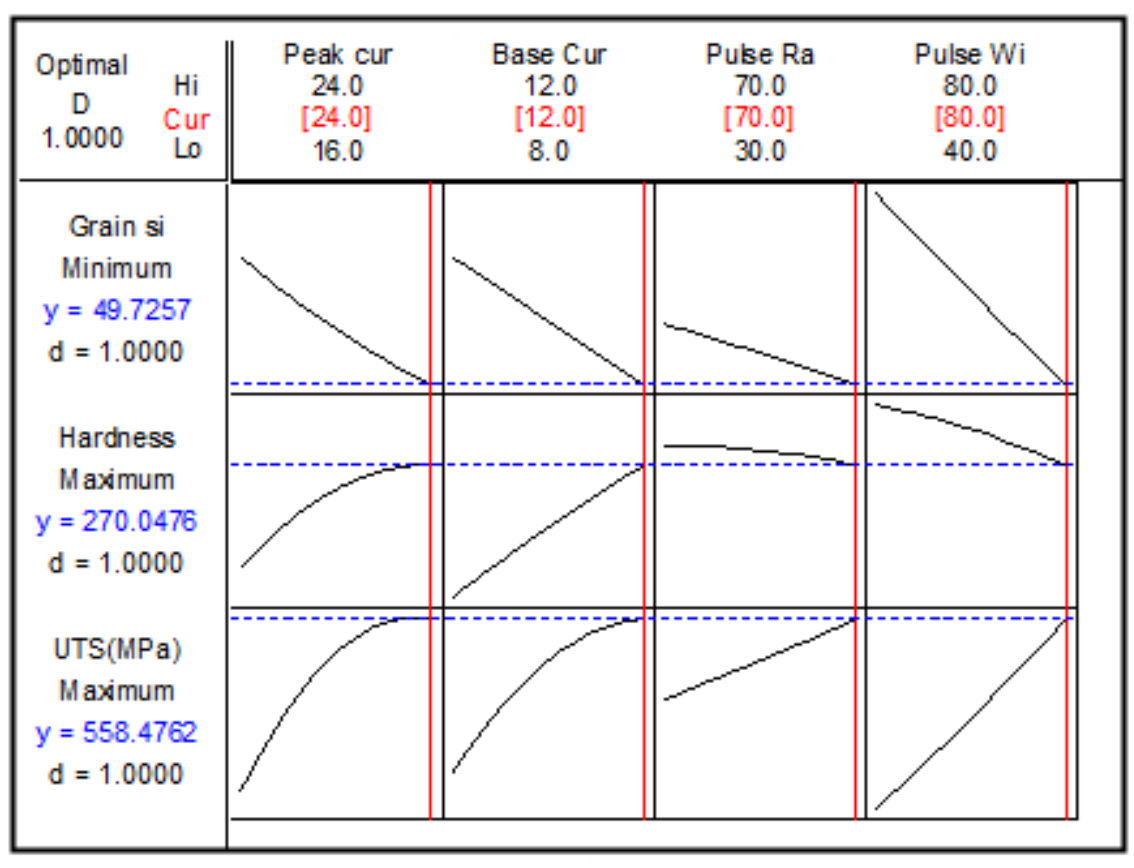

Figure 7. Optimal solution of Surface Response Method

\subsection{Grey Relational Analysis}

The grey system theory was proposed by Deng. The grey means the primitive data with poor, incomplete and uncertain information in the grey systematic theory. The incomplete relation of information among these data is called the grey relation. Grey relational analysis can effectively be recommended as an algorithm for optimising the complicated inter-relationships among multiple performance characteristics. Through the grey relational analysis, a grey relational grade is obtained to evaluate the multiple performance characteristics. As a result, optimisation of the complicated multiple performance characteristics can be converted into the optimisation of a single grey relational grade.

In grey relational analysis, experimental data i.e. measured features of quality characteristics are first normalized ranging from zero to one. The process is known as grey relational generation. Next, based on normalized experimental data, grey relational coefficient is calculated to represent the correlation between the desired and actual experimental data. Then overall grey relational grade is determined by averaging the grey relational coefficient corresponding to selected responses. The overall performance characteristic of the multiple response process depends on the calculated grey relational grade. This approach converts a multiple response process optimisation problem into a single response optimisation situation with the objective function as overall grey relational grade. The optimal parametric combination is then evaluated which would result into highest grey relational grade. The steps followed in the optimisation process are:

(i) Normalizing the experimental responses for all the trials.

The normalized expression (1) corresponding to smaller-the-better criteria is:

$$
\mathrm{y}_{\mathrm{i}}(\mathrm{k})=\frac{\max \mathrm{x}_{\mathrm{i}}(\mathrm{K})-\mathrm{x}_{\mathrm{i}}(\mathrm{K})}{\max _{\mathrm{i}}(\mathrm{K})-\min _{\mathrm{i}}(\mathrm{K})}
$$

where, $\mathrm{k}=1$ to $\mathrm{n} ; \mathrm{i}=1$ to $25, \mathrm{n}$ is the performance characteristic and $\mathrm{i}$ is the trial number.

The normalized expression corresponding to larger-the-better criteria is:

$$
\mathrm{y}_{\mathrm{i}}(\mathrm{k})=\frac{\mathrm{x}_{\mathrm{i}}(\mathrm{K})-\min \mathrm{x}_{\mathrm{i}}(\mathrm{K})}{\max \mathrm{x}_{\mathrm{i}}(\mathrm{K})-\min \mathrm{x}_{\mathrm{i}}(\mathrm{K})}
$$

where $\mathrm{y}_{\mathrm{i}}(\mathrm{k})$ is the value after grey relational generation, $\min \mathrm{x}_{\mathrm{i}}(\mathrm{k})$ is the smallest value of $\mathrm{x}_{\mathrm{i}}(\mathrm{k})$ for $\mathrm{k}^{\text {th }}$ response and $\max$ 
$\mathrm{x}_{\mathrm{i}}(\mathrm{k})$ is the largest value of $\mathrm{x}_{\mathrm{i}}(\mathrm{k})$ for the $\mathrm{k}^{\text {th }}$ response.

(ii) Evaluation of Grey relational coefficient $(\gamma)$.

$$
\gamma\left[\mathrm{y}_{0}(\mathrm{~K}) \mathrm{y}_{\mathrm{i}}(\mathrm{K})=\frac{\Delta_{\min }+\zeta . \Delta_{\max }}{\Delta_{0 \mathrm{i}}(\mathrm{K})+\zeta . \Delta_{\max }}\right.
$$

where $\quad \Delta_{0 \mathrm{i}}(\mathrm{K})=\mathrm{P} \mathrm{y}_{\mathrm{o}}(\mathrm{K})-\mathrm{y}_{\mathrm{i}}(\mathrm{K}) \mathrm{P}$ is the absolute value of the difference between $\mathrm{y}_{\mathrm{o}}(\mathrm{K})$ and $\mathrm{y}_{\mathrm{i}}(\mathrm{K})$

$$
\begin{aligned}
& \Delta_{\min =} \min \min \Delta_{0 \mathrm{i}}(\mathrm{K}) \\
& \Delta_{\max } \max \max \Delta_{0 \mathrm{i}}(\mathrm{K}) \\
& \zeta=\text { distinguished coefficient }
\end{aligned}
$$

(iii) Calculating the Grey relational grade by averaging the Grey relational coefficient.

$$
\xi_{\mathrm{i}}=\frac{1}{\mathrm{n}} \sum_{\mathrm{k}=1}^{\mathrm{n}} \gamma_{\mathrm{i}}(\mathrm{K})
$$

\subsection{Analysis of Grain Size, Hardness, UTS}

The specific targets in the present work are maximum hardness and UTS, minimize grain size. The above targets are prepared according to the specific requirements for manufacturing thin walled metal bellow. Initially, using Equations (1) and (2), experimental data have been normalized to obtain Grey relational generation. The normalized data and $\Delta 0_{i}$ for each of the responses of bead geometry have been furnished in Table 6. The distinguishing coefficient $\zeta$ is substituted into Equation-2 to produce the gray relational coefficient. If all the process parameters are of equal weight, then $\zeta$ becomes 0.5 . The gray relational coefficients and grade values for each experiment of the design matrix are calculated by applying the Equations 2 and 3 and tabulated (Table 7).

To find out the optimum process parameters and their effects on selected output parameters, the mean of the Grey relational grade for each level of the parameter is required. Table 7 indicates the mean of overall grey relational grades. The larger the value of the Grey relational grade, the better is the multi response characteristics. Therefore, the optimal level of the welding parameters is the level with the greatest grey relational grade value. The optimal performance for grain size, hardness and UTS are obtained for the following combination of input parameters: Peak current 22 Amps, Back Current 11 Amps, Pulse Rate 60 pulses/sec, Pulse Width $70 \%$.

Figure 8 indicates the effect of welding parameters on the multi-performance characteristics and the response graph of each level of the welding parameters for the performance. The higher values in Table 8 give the desired quality characteristic. Also, the maximum and minimum values of the grey relational grade show the importance of individual parameter in pulsed current MPAW process. Hence, the order of importance of the welding parameters is base current, peak current, pulse width and pulse rate. 
Table 6. Grey relational generation and $\Delta_{0 \mathrm{i}}$ of each performance characteristics

\begin{tabular}{|c|c|c|c|c|c|c|}
\hline \multirow[t]{2}{*}{ Exp. No. } & \multicolumn{3}{|c|}{ Normalized } & \multicolumn{3}{|c|}{ Deviation Sequence $\left(\Delta_{0 \mathrm{i}}\right)$} \\
\hline & Grain size & Hardness & UTS & Grain size & Hardness & UTS \\
\hline 1 & 0.6250 & 0.3125 & 0.5000 & 0.3750 & 0.6875 & 0.5000 \\
\hline 2 & 0.6875 & 0.5938 & 1.0000 & 0.3125 & 0.4063 & 0.0000 \\
\hline 3 & 0.4844 & 0.6250 & 0.6667 & 0.5156 & 0.3750 & 0.3333 \\
\hline 4 & 0.6328 & 0.9375 & 0.8333 & 0.3672 & 0.0625 & 0.1667 \\
\hline 5 & 0.4375 & 0.2500 & 0.5000 & 0.5625 & 0.7500 & 0.5000 \\
\hline 6 & 0.1953 & 0.5000 & 0.7083 & 0.8047 & 0.5000 & 0.2917 \\
\hline 7 & 0.5469 & 0.6875 & 0.3750 & 0.4531 & 0.3125 & 0.6250 \\
\hline 8 & 0.4375 & 1.0000 & 0.7500 & 0.5625 & 0.0000 & 0.2500 \\
\hline 9 & 0.0156 & 0.2500 & 0.2500 & 0.9844 & 0.7500 & 0.7500 \\
\hline 10 & 0.6250 & 0.3750 & 0.4583 & 0.3750 & 0.6250 & 0.5417 \\
\hline 11 & 0.2344 & 0.2500 & 0.4167 & 0.7656 & 0.7500 & 0.5833 \\
\hline 12 & 0.7813 & 0.9063 & 0.8333 & 0.2188 & 0.0938 & 0.1667 \\
\hline 13 & 0.0000 & 0.0000 & 0.3333 & 1.0000 & 1.0000 & 0.6667 \\
\hline 14 & 0.5938 & 0.0625 & 0.7083 & 0.4063 & 0.9375 & 0.2917 \\
\hline 15 & 0.4844 & 0.1875 & 0.5417 & 0.5156 & 0.8125 & 0.4583 \\
\hline 16 & 1.0000 & 0.8125 & 0.8333 & 0.0000 & 0.1875 & 0.1667 \\
\hline 17 & 0.0469 & 0.0000 & 0.0000 & 0.9531 & 1.0000 & 1.0000 \\
\hline 18 & 0.7500 & 0.4688 & 0.8542 & 0.2500 & 0.5313 & 0.1458 \\
\hline 19 & 0.2969 & 0.1250 & 0.2500 & 0.7031 & 0.8750 & 0.7500 \\
\hline 20 & 0.7500 & 0.9375 & 0.7500 & 0.2500 & 0.0625 & 0.2500 \\
\hline 21 & 0.6094 & 0.5625 & 0.7083 & 0.3906 & 0.4375 & 0.2917 \\
\hline 22 & 0.4375 & 0.4375 & 0.5833 & 0.5625 & 0.5625 & 0.4167 \\
\hline 23 & 0.5313 & 0.7500 & 0.8750 & 0.4687 & 0.2500 & 0.1250 \\
\hline 24 & 0.4125 & 0.2500 & 0.4375 & 0.5875 & 0.7500 & 0.5625 \\
\hline 25 & 0.4531 & 0.5625 & 0.6875 & 0.5469 & 0.4375 & 0.3125 \\
\hline 26 & 0.5156 & 0.6250 & 0.6458 & 0.4844 & 0.3750 & 0.3542 \\
\hline 27 & 0.4531 & 0.5625 & 0.6875 & 0.5469 & 0.4375 & 0.3125 \\
\hline 28 & 0.5938 & 0.6250 & 0.6458 & 0.4063 & 0.3750 & 0.3542 \\
\hline 29 & 0.5313 & 0.5625 & 0.6875 & 0.4687 & 0.4375 & 0.3125 \\
\hline 30 & 0.5938 & 0.6250 & 0.6458 & 0.4063 & 0.3750 & 0.3542 \\
\hline 31 & 0.4844 & 0.6875 & 0.7083 & 0.5156 & 0.3125 & 0.2917 \\
\hline
\end{tabular}


Table 7. Grey relational coefficient and Grey relational grade of Each performance characteristics $(\zeta=0.5)$

\begin{tabular}{|c|c|c|c|c|c|}
\hline \multirow[t]{2}{*}{ Experiment No. } & \multicolumn{3}{|c|}{ Grey Relation Coefficient } & \multirow{2}{*}{$\begin{array}{c}\text { Grey Relation } \\
\text { Grade }\end{array}$} & \multirow[t]{2}{*}{ Rank } \\
\hline & Grain size & Hardness & UTS & & \\
\hline 1 & 0.571 & 0.421 & 0.500 & 0.497 & \\
\hline 2 & 0.615 & 0.552 & 1.000 & 0.722 & \\
\hline 3 & 0.492 & 0.571 & 0.600 & 0.555 & \\
\hline 4 & 0.577 & 0.889 & 0.750 & 0.738 & \\
\hline 5 & 0.471 & 0.400 & 0.500 & 0.457 & \\
\hline 6 & 0.383 & 0.500 & 0.632 & 0.505 & \\
\hline 7 & 0.525 & 0.615 & 0.444 & 0.528 & \\
\hline 8 & 0.471 & 1.000 & 0.667 & 0.712 & \\
\hline 9 & 0.337 & 0.400 & 0.400 & 0.379 & \\
\hline 10 & 0.571 & 0.444 & 0.480 & 0.499 & \\
\hline 11 & 0.395 & 0.400 & 0.462 & 0.419 & \\
\hline 12 & 0.696 & 0.842 & 0.750 & 0.763 & \\
\hline 13 & 0.333 & 0.333 & 0.429 & 0.365 & \\
\hline 14 & 0.552 & 0.348 & 0.632 & 0.510 & \\
\hline 15 & 0.492 & 0.381 & 0.522 & 0.465 & \\
\hline 16 & 1.000 & 0.727 & 0.750 & 0.826 & 1 \\
\hline 17 & 0.344 & 0.333 & 0.333 & 0.337 & \\
\hline 18 & 0.667 & 0.485 & 0.774 & 0.642 & \\
\hline 19 & 0.416 & 0.364 & 0.400 & 0.393 & \\
\hline 20 & 0.667 & 0.889 & 0.667 & 0.741 & \\
\hline 21 & 0.561 & 0.533 & 0.632 & 0.575 & \\
\hline 22 & 0.471 & 0.471 & 0.545 & 0.496 & \\
\hline 23 & 0.516 & 0.667 & 0.800 & 0.661 & \\
\hline 24 & 0.460 & 0.400 & 0.471 & 0.443 & \\
\hline 25 & 0.478 & 0.533 & 0.615 & 0.542 & \\
\hline 26 & 0.508 & 0.571 & 0.585 & 0.555 & \\
\hline 27 & 0.478 & 0.533 & 0.615 & 0.542 & \\
\hline 28 & 0.552 & 0.571 & 0.585 & 0.570 & \\
\hline 29 & 0.516 & 0.533 & 0.615 & 0.555 & \\
\hline 30 & 0.552 & 0.571 & 0.585 & 0.570 & \\
\hline 31 & 0.492 & 0.615 & 0.632 & 0.580 & \\
\hline
\end{tabular}

Table 8. Response table (mean) for overall grey relational grade

\begin{tabular}{ccccc}
\hline LEVEL & Peak Current & Base Current & Pulse Rate & Pulse Width \\
\hline 1 & 0.3369 & 0.3931 & 0.5754 & 0.6609 \\
2 & 0.4581 & 0.4918 & 0.5715 & 0.5894 \\
3 & 0.5526 & 0.5305 & 0.5394 & 0.5347 \\
4 & 0.6594 & 0.6257 & 0.5461 & 0.5282 \\
5 & 0.6419 & 0.7407 & 0.4955 & 0.4435 \\
Delta & 0.3225 & 0.3477 & 0.0799 & 0.2175 \\
Rank & 2 & 1 & 4 & 3 \\
\hline
\end{tabular}




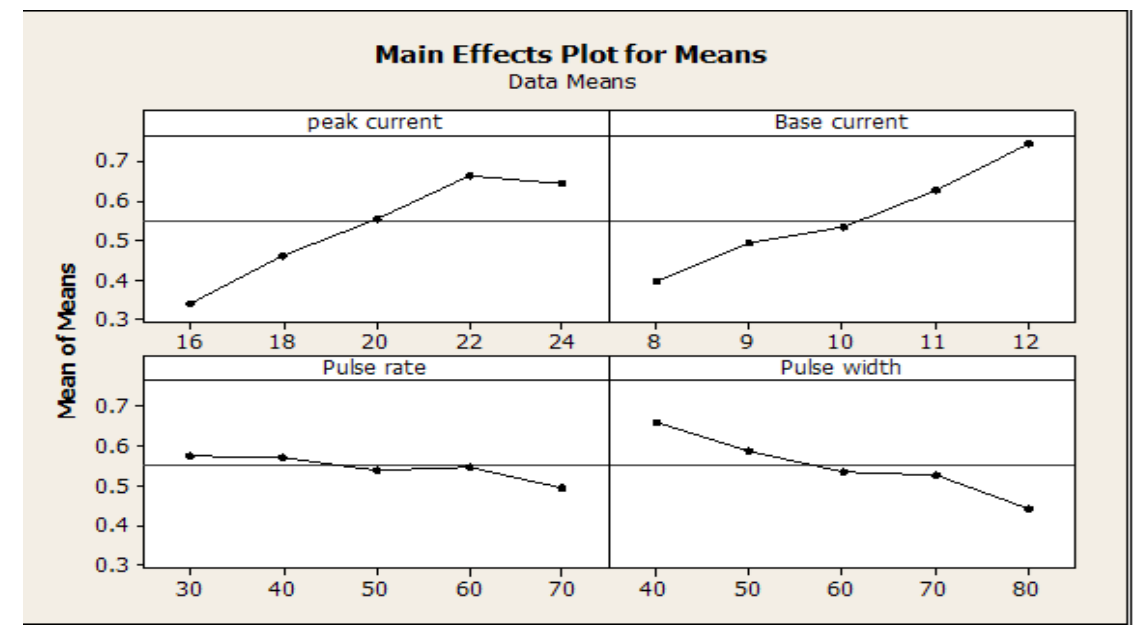

Figure 8. Effect of welding parameters on grey relational grade.

\subsection{Confirmation Experiments for Grey Relational Analysis}

After evaluating the optimal parameter settings, the next step is to predict and verify the enhancement of quality characteristics using the optimal parametric combination. Table 9 shows the comparison of the predicted weld bead geometry parameters with that of actual using the optimal MPAW welding conditions. There is a good agreement between the actual and predicted results (improvement in the overall Grey relational grade).

Table 9. Results of confirmation test for Grey Relational Analysis

\begin{tabular}{ccc}
\hline & Initial Values & Experimental Values \\
\hline Combination & A-4,B-5,C-1,D-1 & A-5,B-4,C-4,D-3 \\
Grain Size & 63.6 & 67.9 \\
Hardness & 273 & 284 \\
UTS & 546 & 584 \\
Grey Relation Grade & 0.826 & 0.884 \\
\hline
\end{tabular}

From Table 9, it is understood that utilization of the optimal welding parameter combination enhances the grey relational grade from 0.826 to 0.884 , i.e. grey relational grade has improved by $5.8 \%$.

\section{Conclusions}

The following conclusions are drawn based on the experiments performed.

1. AISI 904L super austentic steels are butt welded using Micro Plasma Arc Welding at different combinations as per the RSM-CCD Design Matrix.

2. As per Response Surface Method at a peak current of 24 Amperes, Base current of 12 Amperes, pulse rate of 70 pulses/sec and pulse width of $80 \%$, the optimal grain size is 49.7257 Microns, Hardness is 270.0476 VHN and UTS is $558.4762 \mathrm{MPa}$. The optimal combination obtained is not within the 31 combination of experiments performed (Table 5). However, they are within the selected range of welding parameter (Table 4).

3. The optimal performance for grain size, hardness and UTS are obtained for the following combination of input parameters: Peak current 22 Amps, Back Current 11 Amps, Pulse Rate 60 pulses/sec, Pulse Width 70\%. The optimal combinations of input welding parameters are within the chosen 31 combination of experiments (Table 5).

4. The order of importance of the welding parameters is base current, peak current, pulse widthand pulserate.

5. An improvement of 5.8\% is obtained in Grey Relational Grade.

\section{Acknowledgement}

We are thankful to Metallic Bellows(I) PvtLtd, Chennai, India for providing the experimental facility. 


\section{Conflict of interest}

The authors declare no conflict of interest.

\section{References}

[1] Deepashri D. Nage, V. S. Raja, Effect of nitrogen addition on the microstructure and mechanical behaviour of 317L and 904L austenitic stainless-steel welds, J Mater Sci, 41(20), 2006, 97-2112.

[2] Barbara Nasilowska, ZdzislawBogdanowicz, Michal Wojucki, Shot peening effect on 904L welds corrosion resistance, Journal of Constructional Steel Research, 115, 2015, 276-282.

[3] D.D. Nage and V. S. Raja, Examination of Crater Crack Formation in Nitrogen-Containing Austenitic Stainless-Steel Welds, welding research, 2017, 104-112.

[4] K. DevendranathRamkumar, AkashHarendraDagur, Ashwin Anil Kartha, MoharilAtharvaSubodh, C. Vishnu, D. Arun, M. Giridharan Vijay Kumar, Winston Sunny Abraham, AnkitaChatterjee, Jayanthi Abraham, Johann Abraham, Microstructure, mechanical properties and biocorrosion behaviour of dissimilar welds of AISI 904L and UNS S32750, Journal of Manufacturing Processes 30, 2017, 27-40.

[5] P.Sathiya, S.Aravindan, P.M. Ajith1, B.Arivazhagan, A. NoorulHaq, Microstructural characteristics on bead on plate welding of AISI 904L super austenitic stainless steel using Gas metal arc welding process, International Journal of Engineering, Science and Technology, 2(6), 2010, 189-199.

[6] K.DevendranathRamkumar,Jelli Lakshmi NarasimhaVarma, GangineniChaitanya,AyushChoudhary, N. Arivazhagan, S. Narayanan, Effect of autogeneous GTA welding with and without flux addition on the microstructure and mechanical properties of AISI 904L joints, Materials Science \& Engineering A, 636, 2015, 1-9.

[7] P.Manavalan and S.Ravi, R.Kesavan, Identification of optimized welding conditions for pulsed current gas metal arc welding of AISI 904 super austenitic stainless steel, Applied Mechanics and Materials, 787, 2015, 500-504.

[8] K. DevendranathRamkumar, AyushChoudhary, ShivangAggarwal, AnubhavSrivastava,TadikondaHarsha Mohan, and N. Arivazhagan, Characterization of microstructure and mechanical properties of continuous and pulsed current gas tungsten arc welded super austenitic stainless steel, Materials Research Society, 2015, 1-20.

[9] K. DevendranathRamkumar, Shah ViteshNaren, Venkata Rama KarthikPaga,AmbujTiwari, N. Arivazhagan, Development of pulsed current gas tungsten arc welding technique for dissimilar joints of marine grade alloys, Journal of Manufacturing Processes, 383, 2015, 1-13.

[10] Kondapalli Siva Prasad, Ch.Srinivasa Rao, D.Nageswara Rao, Optimization of fusion zone grain size, hardness and ultimate tensile strength of pulsed current micro plasma arc welded Inconel 625 sheets using genetic algorithm, International Journal of Advanced Manufacturing Technology (Springer), Volume 85, Issue 8-12, 2287-2295.

[11] Kondapalli Siva Prasad, Ch.Srinivasa Rao, D.Nageswara Rao, Optimizing Fusion Zone Grain Size and Ultimate Tensile Strength of Pulsed Current Micro Plasma Arc Welded Inconel 625 Alloy Sheets using Hooke \& Jeeves Method, International Transaction Journal of Engineering, Management \& Applied Sciences \&Technologies, Volume 3, No.1, 2012, 87-100.

[12] Kondapalli Siva Prasad, Ch.Srinivasa Rao, D.Nageswara Rao, Effect of pulsed current micro plasma arc welding process parameters on fusion zone grain size and ultimate tensile strength of Inconel 625 sheets, ActaMetallurgicaSinica (English letters), Volume 25,Number 3, 2012, 179-189. 